\title{
Vehnälajikkeiden leivontalaatu
}

Yrjö Salo $^{1)}$, Elina Sieviläinen ${ }^{2}$ ja Lauri Jauhiainen ${ }^{3)}$

${ }^{1)}$ MTT Kasvintuotannon tutkimus, Toivonlinnantie 518,21500Piikkiö,yrjo.salo@mtt.fi

2) Evira, Elintarviketurvallisuusvirasto, Viljantarkastus, Mustialankatu 3, 00790 Helsinki, elina.sievilainen@evira.fi

${ }^{3)}$ MTT Kasvintuotannon tutkimus,31600 Jokioinen, lauri.jauhiainen@mtt.fi

Uusien leipävehnälajike-ehdokkaiden on Suomen lajikelistalle päästäkseen hyväksyttävästi läpäistävä leivontakokeilla tehdyt testit. Vehnälajikkeilla on perimästä johtuvia eroja leivontalaadussa. Syys- ja kevätvehnälajikkeiden leivontalaatua on tutkittu pitkään MTT:n ja Eviran yhteistyönä virallisten lajikekokeiden sadoista.

Suomen virallisia lajikekokeita tehdään eri paikoilla vuosittain uusittavan ohjelman mukaisesti. Tuloksista lasketaan vuosittain viimeisten kahdeksan vuoden tulokset suoravertailuna, niin että lajikkeiden väliset erot ovat vertailukelpoisia keskenään, vaikka lukumäärät vaihtelevat suuresti.

Tässä tarkastellaan lajikkeiden välisiä eroja leivontatestin eri osatekijöissä: jauhot, taikina ja leipä. Leivontakokeet ovat vuosilta 2001-2008. Mittarilajikkeina, joihin muita lajikkeita verrataan, ovat Urho-syysvehnä ja Kruunu-kevätvehnä. Hyvä leivontalaatu koostuu eri tekijöiden kokonaisuuden arvostelusta.

\section{Syysvehnälajikkeet}

Jauhosaanto on ollut paras Larsilla, heikoin Arktikalla ja Rehdillä. Kosteaa sitkoa on ollut runsaimmin Tarsolla ja Tryggvellä. Vähiten sitkoa on ollut lajikkeilla Veeti ja Rehti. Zeleny-luku on ollut paras lajikkeilla SW Magnifik ja Lars. Jauhojen vedensidonta on ollut paras Urholla. Valorimetriluku on ollut paras Tarsolla ja heikon Veetillä.

Taikinan venytysominaisuuksia kuvaava ekstensogrammi on ollut pitkä Olivinilla, Tryggvellä ja SW Magnifikilla, mutta lyhyt Rehdillä. Korkea ekstensogrammi on saatu SW Magnifikilla ja Arktikalla, matala Tryggvellä ja Urholla.

Koeleivonnoissa suurimmat vuokaleivät on saatu Gunbo ja Tryggve-lajikkeilla. Gunbolla on leivän huokoisuus ollut hyvä, mutta kimmoisuus heikko. Kimmoisuus on ollut heikko myös Tryggvellä, mutta Arktikalla hyvä. Gunbon,Tryggven ja Tarson arvoluku on ollut hyvä.

\section{Kevätvehnälajikkeet}

Jauhosaanto on ollut hyvä Amaretolla ja Puntarilla, vaatimaton Wellamolla, Ainolla ja Quarnalla. Kostean sitkon pitoisuus on ollut korkein Anniinalla ja Quarnalla, mutta alhaisin Amaretolla ja Demonstrantilla. Zeleny-luku on ollut hyvä Quarnalla, Bjarnella, Anniinalla ja Wanamolla, mutta alhainen Puntarilla ja Amaretolla. Kevätvehnällä vedensidonta on ollut hyvä Quarnalla, Picololla Anniinalla ja Ainolla, alhainen Puntarilla. Valorimetriluku on ollut hyvä lajikkeilla Quarna, Bjarne, Wanamo, Tjalve, Demonstrant ja Bombona, alhainen Puntari, Amaretto ja Picolo -lajikkeilla.

Eekstensogrammi on ollut korkea Wanamolla ja Quarnalla. Puntarilla, Anniinalla ja Picololla on ollut matala ekstensogrammi. Pitkä ekstensogrammi on ollut monella lajikkeella: Anniina, Tjalve, Bjarne, Zebra ja Bombona.

Koeleivän tilavuus on ollut hyvä Zebra, Anniina, Tjalve ja Bjarne-lajikkeilla. Leivän kokonaisarvostelu, arvoluku on ollut hyvä Puntarilla ja Bjarnella. Anniinan huokoisuus on ollut hyvä, mutta kimmoisuus heikko. Huokoisuus on jäänyt heikoksi Quarnalla. Kimmoisuus on heikko Zebralla, Tjalvella ja Anniinalla.

Asiasanat: vehnälajikkeet, syysvehnälajikkeet, kevätvehnälajikkeet, leivontalaatu, jauhosaanto, sitko, Zeleny, farinogrammi, ekstensogrammi, leipätilavuus 


\section{Johdanto}

Vehnälajikkeet ovat kasvinjalostuksen tuottamia ja lajiketutkimuksen testaamia. Viljelijä viljelee vehnälajikkeita. Viljelyn onnistumiseksi ovat lajikkeen viljelytekniset ominaisuudet tärkeitä. Lajikkeen satotaso ja ne sadon vastaanottajan määrittämät laatuvaatimukset, jotka vaikuttavat hintaan, ovat viljelyn kannattavuuteen vaikuttavia tekijöitä.

Sadon käyttäjät, mylly ja leipomo, pitävät tärkeinä vehnän leivontaominaisuuksia. Näiden ominaisuuksien on oltava hyvät, jotta saadaan kauppaan ja lopulta kuluttajalle hyviä leivontatuotteita.

Koko ketjun, kasvinjalostaja, lajiketutkimus, viljelijä, viljaliike, mylly, leipomo ja kauppa, on tehtävä oma osuutensa lopputavoitteen, käyttötarkoituksen mukaisen laadun tuottamiseksi. Kaikkien ketjun lenkkien pitää tietää, mitkä ominaisuudet ovat vehnän leivontalaadun kannalta tärkeitä. Lajikkeiden väliset erot selvitetään leivontakokeilla. Viljelijän ei pidä tuottaa vain määrää, vaan määrää ja laatua. Myllyvehnän vastaanottovaatimuksina käytetään usein seuraavia vähimmäisarvoja: hehtolitrapaino $78 \mathrm{~kg}$, valkuaispitoisuus $12,5 \%$ ja sakoluku 180. Vastaanottovaatimuksissa on kuitenkin vaihtelua.

\section{Aineisto ja menetelmät}

Vehnälajikkeiden leivontalaatua on tutkittu virallisista lajikekokeista saaduista sadoista vuosittain jo pitkään MTT:n ja Eviran yhteistyönä (Salo ym. 1998). Jauhojen ja taikinan testausmenetelmät ovat kansainvälisten standardien mukaiset ja koeleivontamenetelmä on kehitetty Suomen oloihin (Huttunen ym. 1980). Uuden leipävehnälajike-ehdokkaan on Suomen lajikelistalle (Kasvilajikelautakunnan tiedotteita 2009) päästäkseen, hyvien viljelyominaisuuksien lisäksi, hyväksyttävästi läpäistävä leivontakokeilla tehdyt testit. Vehnillä on kullekin lajikkeelle ominaisia, perimästä johtuvia eroja leivontalaadussa. Rehuvehnälajikkeet eivät sovellu leivonnan raaka-aineeksi. Kokeissa olevat lajikkeet uusiutuvat vuosittain. Joka vuosi jalostajat ja heidän edustajansa esittävät uusia numerolinjoja kokeisiin. Vain osa näistä saa nimen ja pääsee lajikelistalle. Lajikkeiden testaaminen on jatkuvaa.

Aikaisemmin on julkaistu virallisissa lajikekokeissa olleiden vehnälajikkeiden leivontalaatutulokset parivertailuna (Salo ym. 1998). Tuloksia voitiin verrata vain mittarilajikkeen ja vertailtavan lajikkeen välillä. Sekamalli-tilastomenetelmällä laskettuja leivontatuloksia voidaan kaikkien lajikkeiden tuloksia verrata keskenään suoravertailuna. Numeeriset suoravertailutukset julkaistiin ensimmäisen kerran vuonna 2008, MTT:n selvityksiä -sarjassa nro 167 (Kangas ym. 2008). Tässä yhteydessä esitetään sanallisesti ja taulukoissa lajikkeiden eri leivontaominaisuuksia ja lajikeeroja leivontaominaisuuksien suhteen.

Suomen virallisia lajikekokeita tehdään usealla koepaikalla vuosittain uusittavan suunnitelman mukaisesti. Kokeissa oleva lajikevalikoima vaihtelee vuodesta toiseen, joskus jopa saman vuoden kokeissa on hiukan eri lajikkeet. Olennaisinta on valita sellainen tilastollinen menetelmä ja malli, mikä pystyy erottelemaan lajikkeen ja ympäristön vaikutukset toisistaan. Sekamallit soveltuvat tähän, mikäli lajikkeiden vaihtuvuus on kohtuullinen (Searle, 1987). Nyt osa lajikkeista, etenkin ns. mittarilajikkeet, olivat kokeissa useita vuosia peräkkäin. Valitussa sekamallissa lajike oli ainoa ns. kiinteä tekijä, satunnaistekijöitä olivat ympäristöön liittyvät vaikutukset: vuosi, koepaikka ja koe. Tilastollinen analyysi toteutettiin SAS/MIXED -ohjelmalla (versio 9.1.3).

Aineiston vähäisyydestä johtuen joissakin leivonnan kannalta tärkeissä ominaisuuksissa lajikkeiden välisiä eroja ei voida osoittaa tilastollisesti, vaikka niitä varsin todennäköisesti on. Suoravertailutilastolaskennalla saatuja tuloksia voidaan verrata keskenään, vaikka lajikevalikoima vaihtelee suuresti kokeesta toiseen ja kenttäkokeen aikaiset sääolot vaikuttavat leivontalaatuun lajikeominaisuuksien lisäksi. Tässä yhteydessä on käytetty yhteenvetoa vuosilta 2001-2008. Tarkastelussa ovat mukana Suomen lajikelistalla olevat lajikkeet. Mittarilajikkeina ovat Urhosyysvehnä ja Kruunu-kevätvehnä.

Joka vuosi ei saada leipävehnän minimivaatimukset täyttävää satoa koeleivontoihin. Koetulosten perusteella valitaan leivontalaadun täyttävät mittarilajikkeet ja lajike-ehdokkaat koeleivontaan. Vain osasta koesadoista tehdään koeleivonnat. Seuraavassa esitellään niitä syys- ja kevätvehnälajikkeita, joilla on selviä eroja eri ominaisuuksissa muihin lajikkeisiin verrattuna. Hyvä leivontalaatu koostuu eri tekijöiden kokonaisuuden arvostelusta. 


\section{Tulokset}

Taulukko 1. Syysvehnälajikkeiden koeleivonnat, vuodet 2001-2008. Viralliset lajikekokeet.

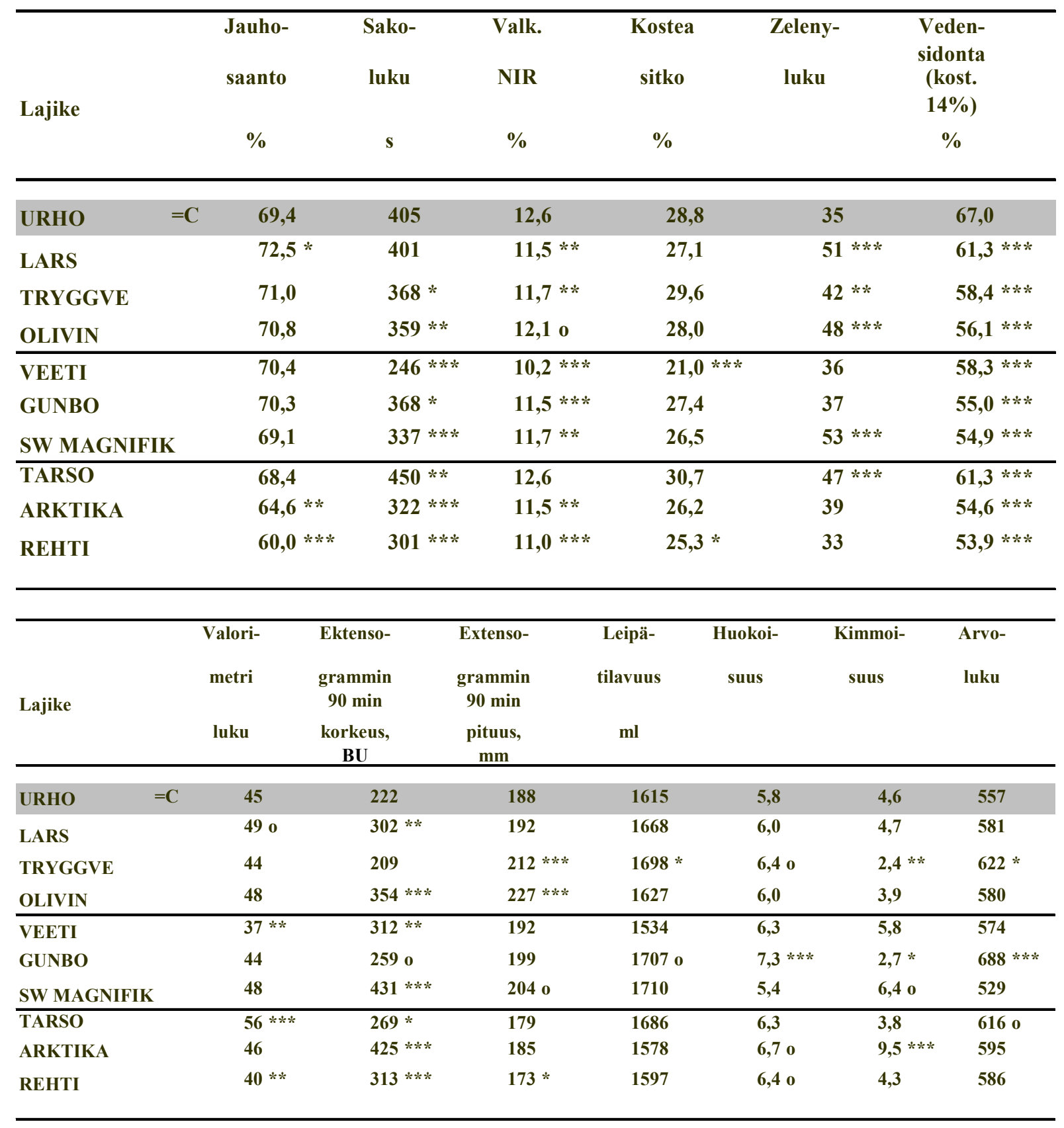

Tilastollinen merkitsevyys: ***(P<0,001), **(P<0,01), $*(\mathrm{P}<0,05)$ ja ${ }^{\circ}(\mathrm{P}<0,10)$. 
Taulukko 2. Kevätvehnälajikkeiden koeleivonat, vuodet 2001-2008. Viralliset lajikekokeet.

\begin{tabular}{|c|c|c|c|c|c|c|}
\hline Lajike & $\begin{array}{c}\text { Jauho- } \\
\text { saanto } \\
\%\end{array}$ & $\begin{array}{l}\text { Sako- } \\
\text { luku } \\
\text { s }\end{array}$ & $\begin{array}{c}\text { Valk. } \\
\text { NIR } \\
\%\end{array}$ & $\begin{array}{c}\text { Kostea } \\
\text { sitko } \\
\text { \% }\end{array}$ & $\begin{array}{c}\text { Zeleny- } \\
\text { luku }\end{array}$ & $\begin{array}{c}\text { Veden- } \\
\text { sidonta } \\
\text { (kost. } \\
14 \% \text { ) } \\
\%\end{array}$ \\
\hline KRUUNU & 70,1 & 354 & 12,4 & 29,2 & 55 & 58,5 \\
\hline AMARETTO & $72,8 * * *$ & $304 * *$ & $11,3 * * *$ & $26,8 * *$ & $42 * * *$ & 58,4 \\
\hline PUNTARI & 72,0 o & $264 * * *$ & $11,4 * *$ & 30,0 & $39 * * *$ & $55,1 * * *$ \\
\hline WANAMO & 70,2 & $417 *$ & $13,5 * *$ & 30,8 & $63 *$ & 57,10 \\
\hline ZEBRA & 69,9 & 352 & $13,0 *$ & 30,4 & $48 * *$ & 58,1 \\
\hline MARBLE & 69,6 & 3180 & 12,6 & 30,9 & $47 * *$ & 58,2 \\
\hline PICOLO & 69,3 & 342 & 12,4 & 28,8 & 55 & $62,3 * * *$ \\
\hline TJALVE & 68,9 & 357 & $13,8 * * *$ & $32,6 * *$ & 59 o & 58,2 \\
\hline BOMBONA & 68,8 & $306 *$ & $13,2 * *$ & 29,7 & 58 & 58,5 \\
\hline EPOS & 68,7 & 379 & 12,2 & 28,0 & 55 & 58,9 \\
\hline МАНТI & 68,5 & 338 & 12,7 & 31,3 o & 57 & 58,5 \\
\hline DEMONSTRANT & 68,4 & 373 & 12,4 & $26,6 *$ & 51 & $56,6 * *$ \\
\hline BJARNE & 68,4 o & $414 * *$ & $14,1 * * *$ & $31,6 *$ & $66 * * *$ & 59,2 \\
\hline ANNIINA & 68,1 & 331 & $15,9 * * *$ & $42,7 * * *$ & $64 * *$ & $61,8 * * *$ \\
\hline QUARNA & $67,6 *$ & $436 * * *$ & $15,0 * * *$ & $34,9 * * *$ & $69 * * *$ & $64,6 * * *$ \\
\hline AINO & $67,1 * *$ & 350 & 12,6 & 27,5 & 57 & $60,2 * * *$ \\
\hline WELLAMO & $66,8 * *$ & 364 & $13,2 * *$ & 29,7 & 56 & $\mathbf{5 7 , 7}$ \\
\hline
\end{tabular}

\begin{tabular}{|c|c|c|c|c|c|c|c|}
\hline Lajike & $\begin{array}{l}\text { Valori- } \\
\text { metri } \\
\text { luku } \\
\end{array}$ & $\begin{array}{c}\text { Ekstenso- } \\
\text { grammin } \\
90 \text { min } \\
\text { korkeus, } \\
\text { BU } \\
\end{array}$ & $\begin{array}{c}\text { Ekstenso- } \\
\text { grammin } \\
90 \mathrm{~min} \\
\text { pituus, } \\
\text { mm } \\
\end{array}$ & $\begin{array}{c}\text { Leipä- } \\
\text { tilavuus } \\
\text { ml }\end{array}$ & $\begin{array}{c}\text { Huokoi- } \\
\text { suus }\end{array}$ & $\begin{array}{l}\text { Kimmoi- } \\
\text { suus }\end{array}$ & $\begin{array}{l}\text { Arvo- } \\
\text { luku }\end{array}$ \\
\hline KRUUNU & 48 & 424 & 208 & 1701 & 6 & 5 & 549 \\
\hline AMARETTO & $44 * *$ & $347 * * *$ & 202 & 1653 & 6 & 6 & 565 \\
\hline PUNTARI & $43 * *$ & $223 * * *$ & 2260 & 1767 & 6 & 5 & 627 * \\
\hline WANAMO & $56 * *$ & $549 * * *$ & 226 & 1743 & 5 & 5 & 571 \\
\hline ZEBRA & 50 & 398 & $235 * *$ & $1859 * *$ & 6 & $3 * * *$ & 6100 \\
\hline$\overline{\text { MARBLE }}$ & 48 & $368 *$ & 202 & 1722 & 6 & 5 & 6070 \\
\hline PICOLO & $44 *$ & $301 * * *$ & 212 & 1633 & 5 & $4 *$ & 541 \\
\hline TJALVE & $53 * * *$ & 442 & $247 * * *$ & $1810 * *$ & 5 & $3 * *$ & 571 \\
\hline BOMBONA & $52 * *$ & 442 & $230 *$ & 1755 & 5 & 5 & 579 \\
\hline EPOS & 510 & $343 * *$ & 2240 & 1736 & 5 & $4 *$ & 577 \\
\hline МАНТI & 48 & 409 & 216 & 1727 & $6 *$ & 4 & 6190 \\
\hline DEMONSTRANT & $53 * *$ & 435 & 212 & 1649 & 6 & 5 & 565 \\
\hline BJARNE & $58 * * *$ & 443 & $242 * * *$ & 1780 * & 6 & $4 *$ & 613 * \\
\hline $\begin{array}{l}\text { ANNIINA } \\
\text {. }\end{array}$ & 50 & $257 * * *$ & $263 * * *$ & $1858 * *$ & 7 * & $3 *$ & 625 \\
\hline QUARNA & $60 * * *$ & $548 * * *$ & 220 & 1739 & $4 * * *$ & $4 *$ & 493 \\
\hline AINO & 46 & 376 * & 202 & & 5 & $4 *$ & 555 \\
\hline WELLAMO & 510 & 423 & 213 & 1659 & 5 & 5 & 537 \\
\hline
\end{tabular}

Tilastollinen merkitsevyys: $* * *(\mathrm{P}<0,001),{ }^{* *}(\mathrm{P}<0,01),{ }^{*}(\mathrm{P}<0,05) \mathrm{ja}{ }^{\circ}(\mathrm{P}<0,10)$. 


\section{Tulosten tarkastelua ja johtopäätökset}

\section{Syysvehnälajikkeet}

Jauhosaanto, joka on jauhetusta jyvämäärästä saatu jauhon määrä prosentteina, on kokeissa ollut paras Lars-lajikkeella, mutta heikoin Arktikalla ja Rehdillä.

Kosteaa sitkoa on ollut runsaimmin Tarsolla ja Tryggvellä. Vähiten sitkoa on ollut lajikkeilla Veeti ja Rehti. Zeleny-luku, joka kertoo sitkon määrästä ja laadusta, on ollut paras lajikkeilla SW Magnifik ja Lars.

Jauhojen vedensidonta on ollut paras Urholla. Valorimetriarvo on empiirinen arvo, joka ilmaisee lähinnä taikinan muodostumisaikaa ja sekoituskestävyyttä. Valorimetriluku on ollut paras Tarsolla ja heikon Veetillä.

Taikinan venyvyyttä ja venytysvastusta määritetään ekstensogrammilla. Taikinan venyvyys eli ekstensogrammin muoto on hyvällä, kimmoisalla sitkolla korkea ja pitkä. Ekstensogrammi on ollut pitkä Olivinilla, Tryggvellä ja SW Magnifikilla, mutta lyhyt Rehdillä. Korkea ekstensogrammi on saatu SW Magnifikilla ja Arktikalla. Matala käyrä on ollut Tryggvellä ja Urholla.

Koeleivonnoissa suurimmat vuokaleivät on saatu Gunbo ja Tryggve-lajikkeilla. Gunbolla on leivän huokoisuus ollut hyvä, mutta kimmoisuus heikko. Kimmoisuus on ollut heikko myös Tryggvellä, mutta Arktikalla hyvä. Gunbon,Tryggven ja Tarson arvoluku on ollut hyvä.

\section{Kevätvehnälajikkeet}

Jauhosaanto on ollut hyvä Amaretolla ja Puntarilla, vaatimaton Wellamolla, Ainolla ja Quarnalla. Kostean sitkon pitoisuus on ollut korkein Anniinalla ja Quarnalla, mutta alhaisin Amaretolla ja Demonstrantilla. Sitkopitoisuus kuvaa paljonko jauhossa on sitkoa eli gluteenia. Sitkon määrän lisäksi myös lajikkeen leivontalaatua kuvaava Zeleny-luku on ollut hyvä Quarnalla, Bjarnella, Anniinalla ja Wanamolla, mutta alhainen Puntarilla ja Amaretolla.

Jauhojen vedensidonta kuvaa taikinatulosta ja on vesimäärä, joka tarvitaan valmistettaessa määrätyn kiinteyden omaava taikina. Jauhojen vedensidontakyky on yleensä sitä suurempi mitä korkeampi on jauhojen proteiinipitoisuus ja mitä vahvempi on sitko. Kevätvehnällä vedensidonta on ollut hyvä Quarnalla, Picololla Anniinalla ja Ainolla, alhainen Puntarilla.

Valorimetriluku on ollut hyvä lajikkeilla Quarna, Bjarne, Wanamo, Tjalve, Demonstrant ja Bombona, alhainen Puntari, Amaretto ja Picolo -lajikkeilla. Eekstensogrammi on ollut korkea Wanamolla ja Quarnalla. Puntarilla, Anniinalla ja Picololla on ollut matala ekstensogrammi. Pitkä ekstensogrammi on ollut monella lajikkeella: Anniina, Tjalve, Bjarne, Zebra ja Bombona.

Koeleivän tilavuus on ollut hyvä Zebra, Anniina, Tjalve ja Bjarne-lajikkeilla. Leivän kokonaisarvostelu, tilavuuden ja huokoisuuden mukaan saatava arvoluku on ollut hyvä Puntarilla ja Bjarnella. Anniinan huokoisuus on ollut hyvä, mutta kimmoisuus heikko, johtuen mahdollisesti lajikkeen vahvasta sitkosta ja riittämättömästä taikinan sekoituksesta. Huokoisuus on jäänyt heikoksi Quarnalla. Kimmoisuus on heikko Zebralla, Tjalvella ja Anniinalla. 


\section{Kirjallisuusluettelo}

Huttunen, R. Korkman, M., Koskinen, K. \& Lallukka, U. 1980. Vehnän laadun arvostelu. Menetelmän kehittelyä. Viljantutkimustoimikunta ja Valtion viljavarasto Tutkimuslaboratorio. Tiedonantoja 6/80. 32 p.

Kangas, A., Laine, A., Niskanen, M., Salo, Y., Vuorinen, M., Jauhiainen, L. \& Nikander, H. 2008. Virallisten lajikekokeiden tulokset 2001-2008 : Results of official variety trials 2001-2008. MTT:n selvityksiä 167: 196 s. [Url] Verkkojulkaisu päivitetty 19.12.2008

Kasvilajikelautakunnan tiedotteita. 2009. Meddelanden från Finska Växtsortsnämnden | Finnish PlantVariety Journal. 2009:1. 14.8.2009 www.evira.fi/uploads/WebShopFiles/1253600878703.pdf

Salo, Y., Kontturi, M., Talvitie, H. \&, Kartio, M. 1998. Vehnälajikkeiden leivontalaatu virallisissa lajikekokeissa 1988-1994. Maatalouden tutkimuskeskuksen julkaisuja. Sarja A 32: 29 p. + 12 liitettä. [Url] [ Tiivistelmä ] [ $\underline{\text { Abstract }] ~}$

Searle S. R. 1987. Linear Models for Unbalanced Data. John Wiley \& Sons Inc. 